\title{
Investigation on the application of YAG laser texturing technology to the cylinder wall of auto engine
}

\author{
Fian Zhan and Mingjiang Yang \\ Institute of Mechanics, Chinese Academy of Sciences, Beijing, China
}

\begin{abstract}
Purpose - The purpose of this study was to develop a new approach using a pulse YAG laser with rational power density and pulse width to texture desired discrete distribution morphology on the cylinder wall.

Design/methodology/approach - Variational rules of the effects of these three parameters were found by calculating the oil film on the cylinder/piston ring system. The experiment results were compared between laser texturing cylinders and conventional honing cylinders.

Findings - It was found that the coefficient of friction and wear rate of laser texturing cylinders were reduced by 50 and 85.7 per cent, respectively, and the piston ring wear rate was decreased by 50 per cent under full lubrication condition. Under starved lubrication condition, the cylinder liner wear was reduced by 34.3 per cent.

Originality/value - The effectiveness of which was determined by three control parameters: depth-to-diameter ratio, area density and distribution angle of the dimples.
\end{abstract}

Keywords Laser texturing, Depth-to-diameter ratio, Distribution angle, Area density, Friction and wear characteristics

Paper type Research paper

\section{Introduction}

Cylinder liner and piston rings worked in high-temperature, high-speed and high-pressure conditions are prone to all kinds of wear. Since 1990, researchers have studied the effect on friction and wear behavior of laser-textured micro-morphology, which could increase hydrodynamic lubrication oil load capability and reduce friction coefficient of cylinder wall-piston ring. Laser-textured cylinder walls included two main morphologies: one was grooves, which was beneficial to the removal of loose material particles, and the other was dimples, for increasing the oil reservoir and load capacity, leading to increased collection ability of the wear particles.

Most of the total engine friction, about 50-60 per cent, comes from the cylinder/piston ring system. The service life of the engine depends to a large extent on this friction system. The friction and wear characteristics of the cylinder/piston ring system have long been the focus of related research works.

Ronen et al. (2001) studied the piston ring/cylinder system with laser surface-textured (LST) piston rings. It was found that a friction reduction of 30 per cent or more was feasible with textured surfaces. Ryk et al. (2002) found good correlation in a subsequent experimental work. Two

The current issue and full text archive of this journal is available at www.emeraldinsight.com/0036-8792.htm

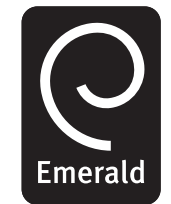

Industrial Lubrication and Tribology 66/3 (2014) 387-392

(C) Emerald Group Publishing Limited [ISSN 0036-8792] [DOI 10.1108/ilt-12-2011-0109]
LST modes are available for reducing the friction loss. The first is piston ring LST mode (concept proposed by Kligerman et al., 2005) and the second is cylinder wall LST mode. Ryk et al. (2005) found that with LST barrel-shaped rings, the reduction in friction was much less than that with a flat-shaped specimen. Yu et al. (2002) found that the friction torque and friction coefficient of laser-textured mechanical seals with a porous face were much lower compared with conventional mechanical seals. Kovalchenko et al. (2004, 2005) studied the impact of LST on lubrication regime transitions and found that the beneficial effects of LST were more pronounced at higher speeds and loads and for oils with higher viscosity. Rapoport et al. (2008) studied the effect on the tribological properties of solid lubricant surfaces where micro-reservoirs were produced by laser surface texturing under dry friction. It was shown that the adhesion of solid lubricant in the space between the dimples was provided by mechanical engagement of particles in the rough surface and by smearing the solid lubricant around the dimples. Meng et al. (2010) found that the friction force for the parallel surfaces could decrease due to the dimple effect over the range of the larger sliding speed, larger load or smoother surfaces. Additionally, for the smaller sliding speed or the smaller load, the effect of the dimples on the friction force became weak, and even could be ignored.

Since 2000, the Laser Texturing Center at the Institute of Mechanics, Chinese Academy of Sciences, has reached a conclusion that the process of texturing micro-pits could, by using laser texturing technology, achieve fast speed and high efficiency, which had important significance to internal combustion engine. This paper investigated the effects on friction and wear characteristics of different laser texturing dimples' distributions on the cylinder wall. 


\section{Main controllable parameters of laser-textured dimples on the cylinder wall}

After the dimples were textured on the cylinder liner wall by laser beams, the variable parameters were the dimples' diameter, 2r $\mathrm{r}_{\mathrm{p}}$; dimples' depth, hp; area density, $\mathrm{S}_{\mathrm{p}}$ $\left(\pi r_{p}^{2} /\left(2 r_{1}\right)^{2}\right)$, which is the ratio of the dimples' area to the total laser texturing area; and distribution angle, $\theta$, as seen in Figure 1, which could describe very well the morphology of one dimple and the distribution of multiple dimples.

For reducing the experimental difficulty and times, the diameter of the dimples was kept at a certain constant value in this work. So, the effect of hp would be reflected in the depth-to-diameter ratio $\varepsilon\left(\mathrm{hp} / 2 \mathrm{r}_{\mathrm{p}}\right)$. It was found that the dimple parameters affecting the friction and wear characteristics were $\varepsilon, S_{p}$ and $\theta$. In this work, the friction and wear characteristics of the whole cylinder liner/piston ring system were studied for three controllable laser-textured dimple parameters, i.e. $\varepsilon, \mathrm{S}_{\mathrm{p}}$ and $\theta$ on the cylinder wall, under two extreme conditions, one was full lubrication and high reciprocation velocity condition and the other was starved lubrication and low reciprocation velocity condition.

\section{Lubrication theory for cylinder liner/piston ring system with laser-textured dimples}

Figure 1(b) gave the geometry of a single-unit cell with a dimple morphology. Assuming a thin Newtonian lubrication film undergoing laminar, incompressible flow and neglecting temperature and inertial effects, the oil film pressure $\mathrm{P}$ of the system under full lubrication and high reciprocating velocity condition could be calculated by the following Reynolds equation (1). Because the clearance between ring and cylinder liner varied with time during each cycle of the ring reciprocal motion, the equation of piston ring radial motion was given by equation (3).

$$
\frac{\partial}{\partial x}\left(h^{3} \frac{\partial P}{\partial x}\right)+\frac{\partial}{\partial y}\left(h^{3} \frac{\partial P}{\partial y}\right)=6 \mu U \frac{\partial h}{\partial x}+12 \mu \frac{\partial h}{\partial t}
$$

Here, $\mathrm{h}$ is lubrication oil film thickness, which was calculated by equation (2), $c(t)$ is the minimum oil film thickness,

Figure 1 Schematic diagram of laser-textured dimples on the cylinder wall (a) and a single dimple (b)

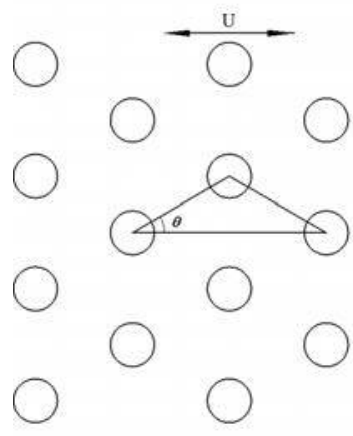

(a)

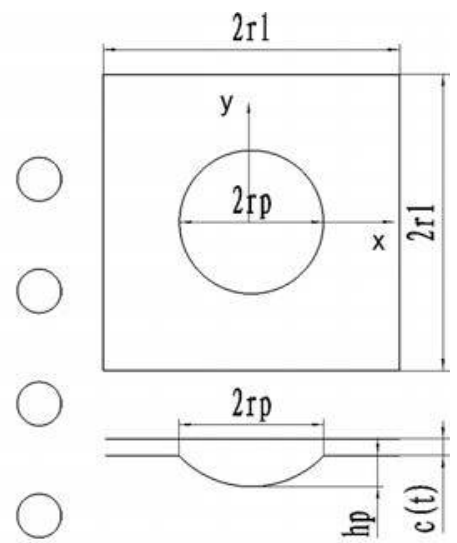

(b)
$F_{h}=\int_{A} P d A$ is the capacity of the lubrication oil, $\mathrm{Fe}$ is the operating normal load of the system, $\mu$ is the viscosity of lubrication oil and $U$ is the system's reciprocating velocity given in equation (4). In this test, $\mathrm{Fe}$ was $13.72 \mathrm{MPa}$. Equation (5) was the boundary condition used for calculation.

$$
\begin{gathered}
h(t)=c(t)+h_{p}-h_{p}\left(x^{2}+y^{2}\right) / r_{p}^{2} \text { (in dimples); } \\
h(t)=c(t) \text { (others) } \\
m \frac{\partial^{2} c(t)}{\partial t^{2}}=F_{h}-F_{e} \\
\mathrm{U}=r_{c} \omega\left(\sin \theta+\frac{r_{c}}{2 l_{c}} \sin 2 \theta\right) \\
\mathrm{x}=-r_{l}, \mathrm{P}=0 ; x=r_{l}, P=0, P\left(\mathrm{x},-r_{l}\right)=P\left(x, r_{l}\right) ; \\
\frac{\partial P}{\partial x}\left(\mathrm{x},-r_{l}\right)=\frac{\partial P}{\partial x}\left(\mathrm{x}, r_{l}\right)
\end{gathered}
$$

$P$ was calculated by finite difference method, in which $r_{p}=60 \mu \mathrm{m}$ and $r_{1}=120 \mu \mathrm{m}$, and the results are shown in Figures 2 and 3.

The results showed that when the values of $\varepsilon, \mathrm{S}_{\mathrm{p}}$ and $\theta$ were varied in the range of $0.1-0.2,20-35$ per cent and $45^{\circ}-60^{\circ}$, respectively, the average hydrodynamic lubrication oil load capability of dimples was better compared with other cases under full lubrication condition.

Figure 2 Relationship between the average capacity and $\varepsilon$

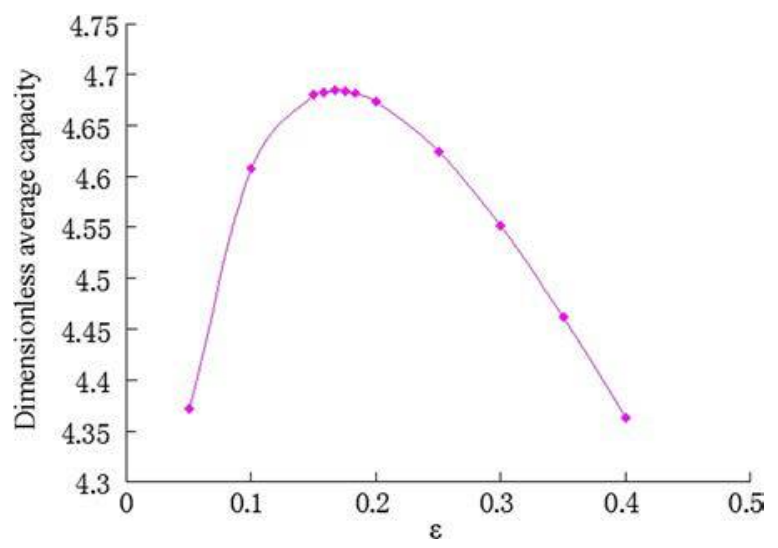

Figure 3 Relationship between the average capacity and $\theta$

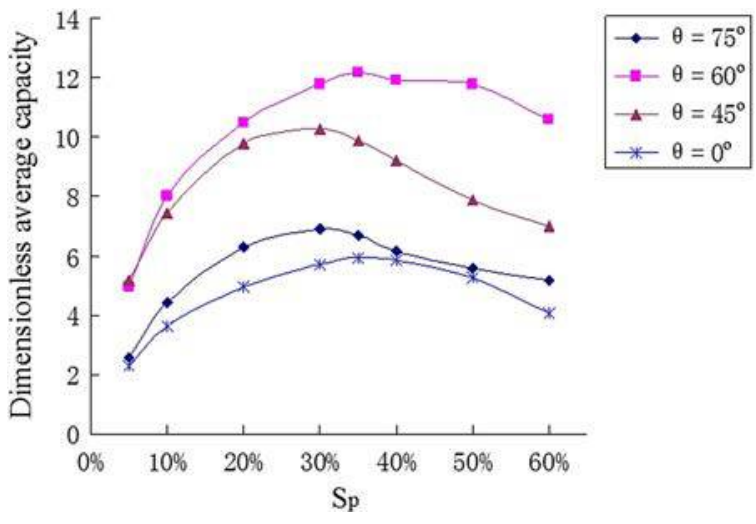




\section{Description of the laser texturing technology}

The cylinder was fixed on the four-jaw chuck of the machine, and the YAG pulse laser passed through the optical guidance system to process its wall, as seen in Figure 4. By adjusting the pulse laser parameters, different $\varepsilon$ (texturing dimple depth-to-diameter ratio) was achieved. At the same time, as the coaxial encoder with 100,000 lines accuracy was installed on the machine, the dimples' density and distribution angle were controlled by altering the machine parameters, such as dot pitch, screw pitch and rotating speed.

In this test, the dimples were produced by a $5-\mathrm{kHz}$ pulsating $\mathrm{Nd}$ :YAG laser with a power of $200 \mathrm{~W}$. In this test, the material of the cylinder liner was not changed and the laser processing parameters were the same, so the depth and width of the dimples were uniform. By laser texturing waveform modulation technology, the laser pulse power density was controlled in the range of $2.5 \times 10^{7}-5 \times 10^{7} \mathrm{~W} / \mathrm{cm}^{2}$ (Figure 5), with the pulse width in the range of 1-10 $\mu \mathrm{s}$, and thus the aforementioned requirement on the morphology of the dimples was satisfied, which had not only a certain depth but also a narrow recast layer, as shown in Figure 6(a). Figure 6 (b) shows the profile of a single dimple by laser etching, and

Figure 4 Laser-texturing device

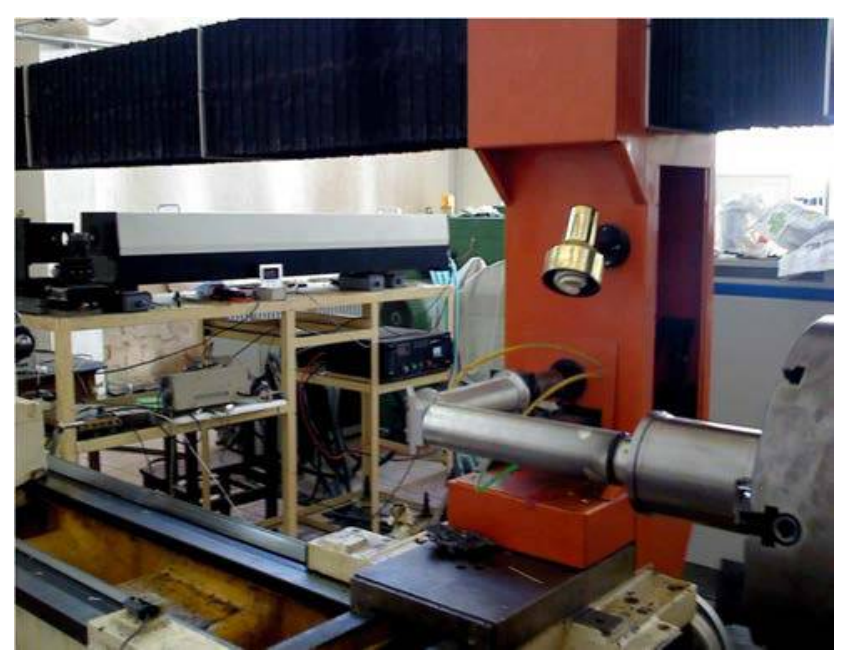

Figure $\mathbf{5}$ Laser pulse waveform

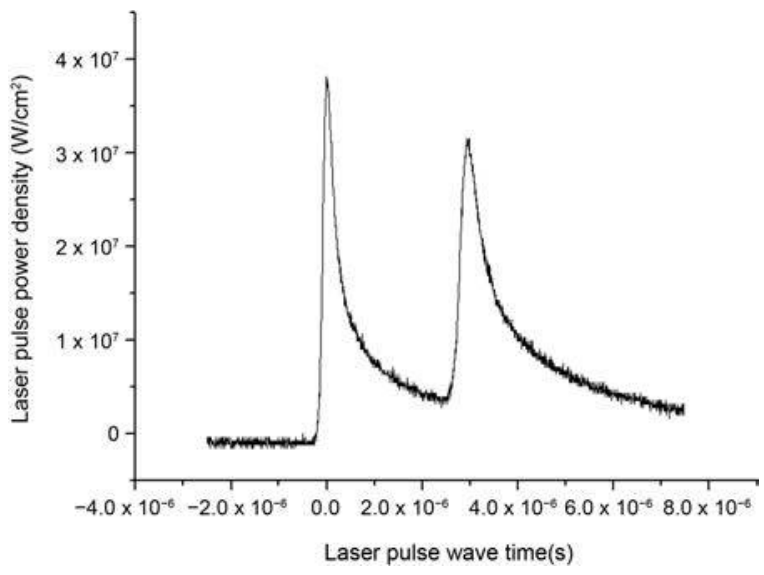

the recast layer was hard to see. This was because the workpiece surface's material in this test was mainly gasified and not melted under the laser power density $\left(2.5 \times 10^{7}-5 \times 10^{7}\right.$ $\left.\mathrm{W} / \mathrm{cm}^{2}\right)$ and pulse width $(1-10 \mu \mathrm{s})$. Even so, there were a small amount of bulges, and post-texturing lapping to remove the bulges at the rim of the dimples was required. All samples' dimples were textured and then polished to remove the molten rim around the dimple.

\section{Friction and wear test}

According to the reciprocating sliding conditions and the characteristics of the cylinder/piston ring system, the frictional district of cylinder wall could be divided into two parts. The first one was TDC, where the lubrication oil film was not easy to retain, the velocity of the reciprocating movement was low and the surface was badly worn. The functions of dimples were mainly collection of wear particles and storage of lubrication oil, so that wear of the system could be reduced. And thus in this district, the main effect of dimples was wear reduction. The second one was the central and thereafter sections of the cylinder, where the oil film was thick enough; the role of dimples was to increase the load capability of the oil film, so that the friction coefficient of the system could be reduced. And thus in this district, the main effect of dimples was friction reduction.

\subsection{Test under full lubrication condition}

The cylinder-piston ring of XiChai6107 engines was selected as the sample for friction pair, and the piston ring test block was selected at a length of $10 \mathrm{~mm}$ by the first ring, as seen in Figure 7. Figure 8(a) showed the original surface of the cylinder wall; the roughness was $0.393 \mu \mathrm{m}$. After laser texturing, the cylinder was cut into blocks, and then the surface bulges were removed, as seen in Figure 8(b).

Through experiments on the cylinder liner-piston ring block under reciprocating movement, the friction and wear characteristics were investigated for the friction pair with the cylinder wall textured by laser beams. Figure 9 shows the schematic diagram of the experiment. The piston back pressure was loaded directly by a loading device, and the piston rings were reciprocally sliding on the cylinder block by motor crank drive. The lubrication oil between the friction pair was rich, which was provided by oil flowing via a guiding oil hole with a certain speed from an oil cup.

The ultimate load was $13.72 \mathrm{MPa}$, the maximum speed was $960 \mathrm{r} /$ minute, the effective sliding distance was $160 \mathrm{~mm}$ per revolution, the adding rate of oil was 1 drop/ $1 \mathrm{~s}$ and the type of lubrication oil was Mobil-10W30. The total test time was 8 hours. The dimple parameters were: $\varepsilon=0.18, \mathrm{~S}_{\mathrm{p}}=20$ per cent and $\theta=60^{\circ}$. The test results are shown in Figures 10-12. Compared with mechanical honing, the friction coefficient and wear of the cylinder liner/piston ring system were reduced by 50 and 85.7 per cent, respectively, and the wear of the corresponding piston ring was reduced by more than 50 per cent. The results also explained that the effect of dimples by laser etching was to improve the cylinder/piston ring system's lubrication condition, which caused the system's friction coefficient and wear to decrease accordingly. By only increasing the cylinder's micro-hardness, the wear of cylinder could be reduced, but the piston ring's wear and the system's friction coefficient cannot be reduced. 
Figure 6 Morphology of the dimples

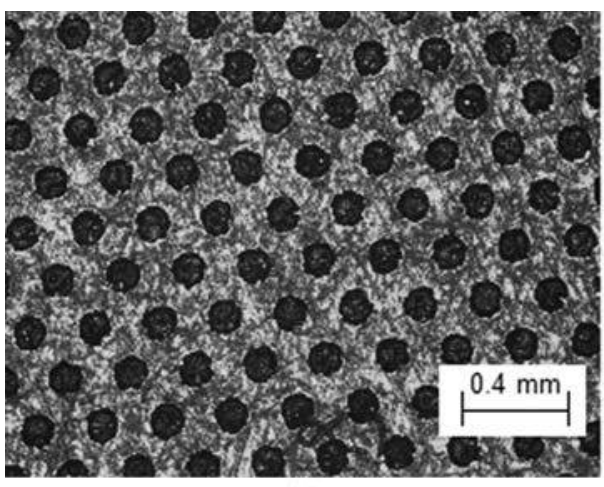

(a)

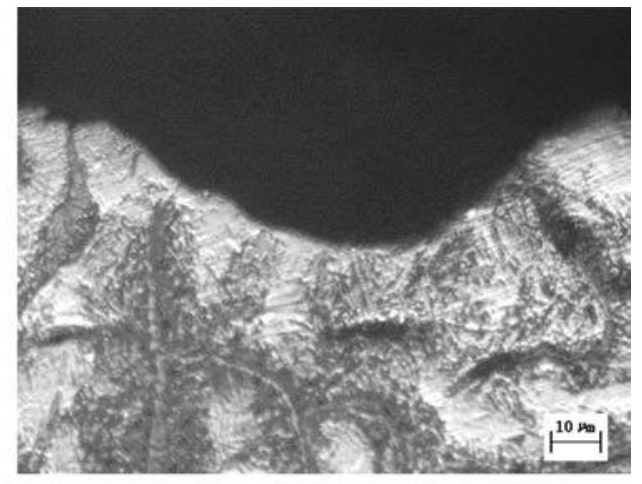

(b)

Notes: (a) Dimples etched on the cylinder wall; (b) profile of a single dimple

Figure 7 The test block of the cylinder and piston ring

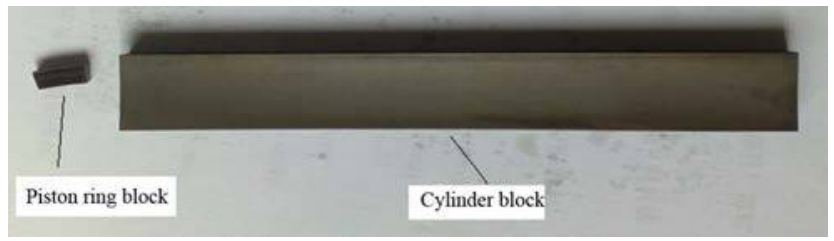

5.2 Test under starved lubrication condition

A cylinder liner-piston ring friction and wear tester was used in the current study, as shown schematically in Figure 13. The cylinder liner was fixed on a fixture, which supplied the up and down reciprocating movement. The piston ring was connected to two symmetrical disc springs by using a hydraulic equipment which supplied load on the frictional pairs' surface with a pressure sensor. The friction of the cylinder liner/piston ring system was recorded by a friction sensor, and the displacement and temperature of the test cylinder liner were controlled by a computer. The total quantity of lubrication oil was limited, and the test conditions were set as follows:

- the frequency was $4 \mathrm{~Hz}$;

- the stroke was $6 \mathrm{~mm}$;

- the maximum load was $85 \mathrm{MPa}$

- the total experimental time was 10 hours, in which the test ran for 4 hours with an oil feeding rate of 1 drop/10 s, and for 6 hours with zero feeding rate; and

- the temperature value of the cylinder wall was kept at $100^{\circ} \mathrm{C}$ throughout the test.

The dimples could store the lubrication oil and collect wear particles, which would reduce total wear of the system. The oil storage capacity depends on dimples' depth, diameter ratio and area density, and the wear-particles-collecting capacity depends on the dimples' distribution angle. The best dimple parameters under starved lubrication condition were not the focal point in this test, so the dimple parameters were the same as mentioned earlier.

The test results are shown in Figure 14. Compared with mechanical honing, the wear scar depth of the textured cylinder wall was reduced by 34.3 per cent.
Figure 8 Surface topography of the cylinder wall

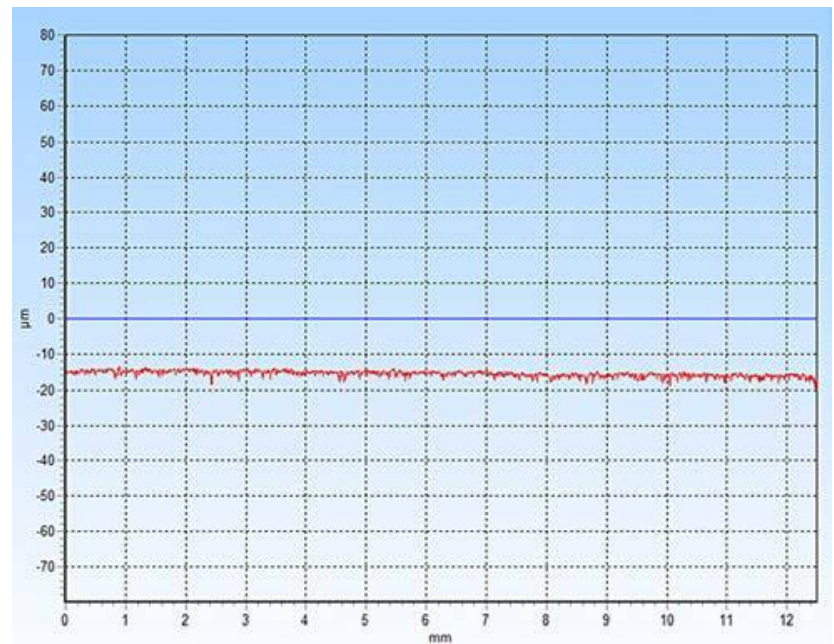

(a)

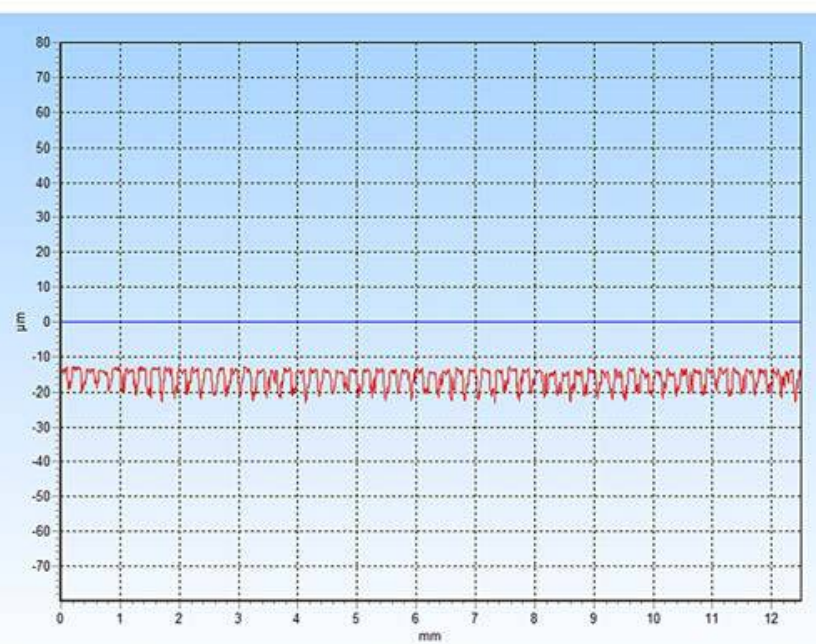

(b)

Notes: (a) After mechanical honing; (b) after laser texturing 
Figure 9 Cylinder-piston ring reciprocating test machine
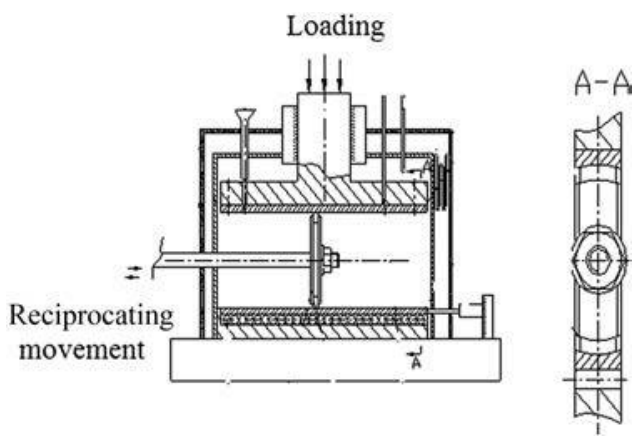

Figure 10 Friction coefficient curve

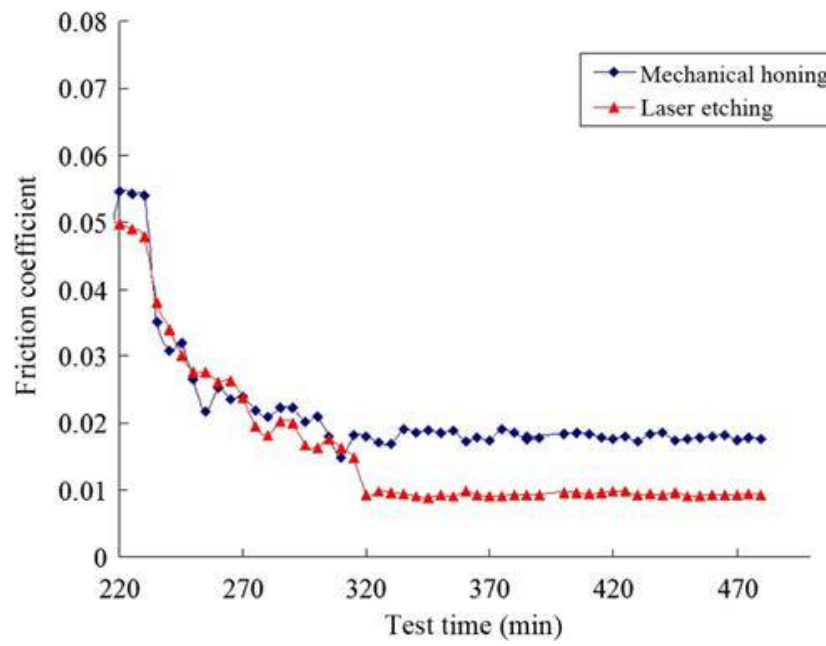

Figure 11 Wear of the cylinder test block

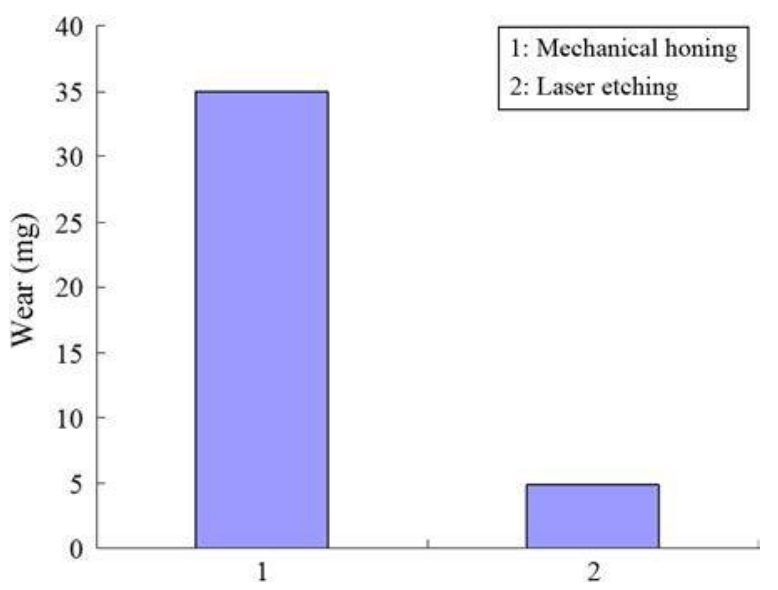

\section{Conclusions}

The dimples with well-selected textured morphology parameters on the cylinder wall could reduce the friction coefficient and wear rate of the cylinder liner/piston ring system and improve the dynamic performance of the engine.

The ranges of parameters adopted in the present laser texturing were laser pulse duration of 1-10 $\mu$ s and power density of $2.5 \times 10^{7}-5 \times 10^{7} \mathrm{~W} / \mathrm{cm}^{2}$.
Figure 12 Wear of the piston ring block

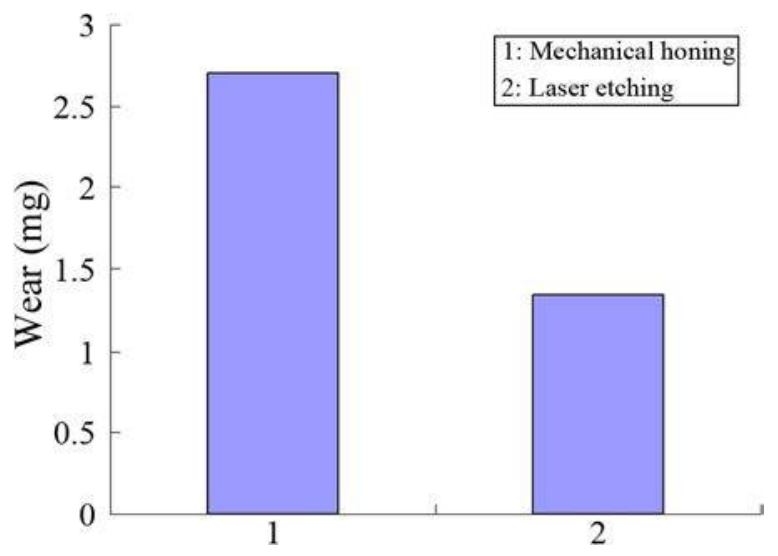

Figure 13 Schematic diagram of the friction test rig

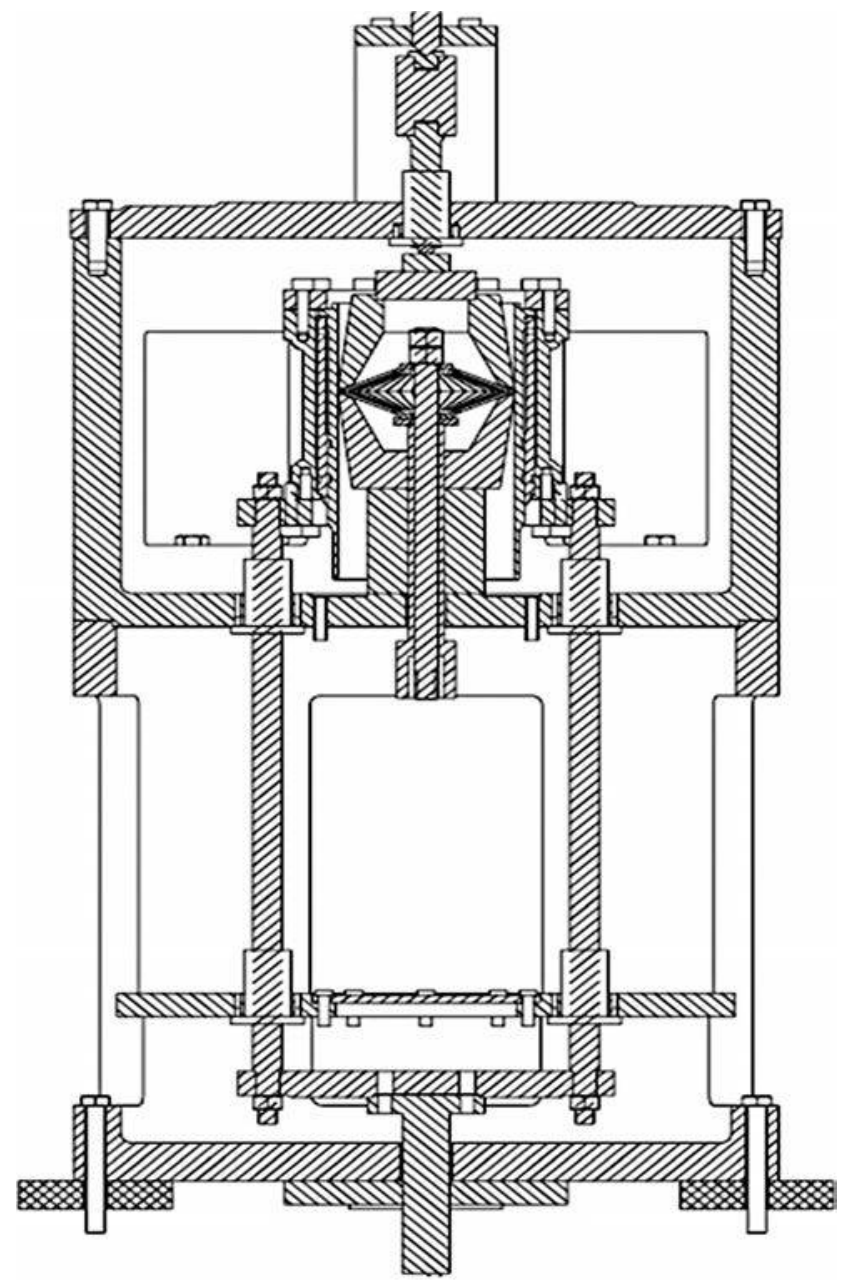

Based on the lubrication theory, the ranges of dimple parameters on the cylinder wall used for the laser texturing were selected as follows: $\varepsilon=0.1-0.2, \mathrm{~S}_{\mathrm{p}}=20-40$ per cent and $\theta=45^{\circ}-60^{\circ}$.

According to the friction and wear test results, under the full lubrication condition, compared with mechanical honing, the laser texturing technique could reduce the friction coefficient 
Figure 14 Wear scar depth

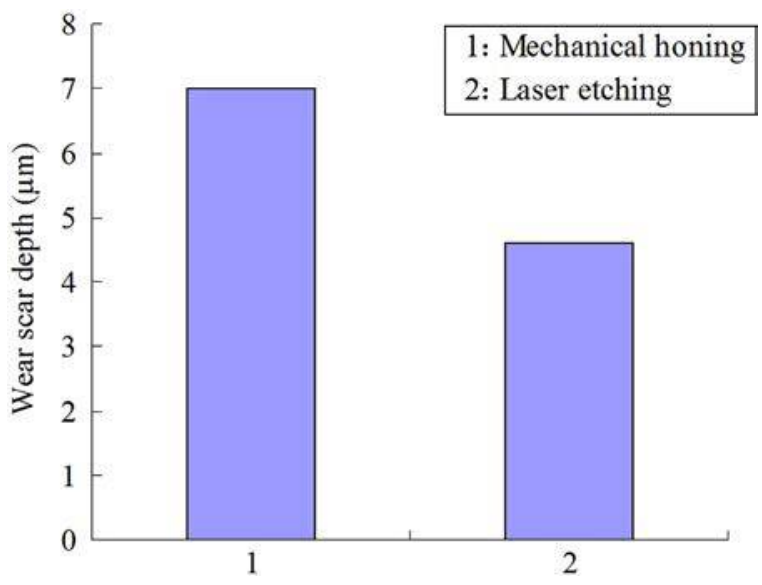

of the cylinder-piston ring by 50 per cent, and reduce the wear of the cylinder and the piston ring by 87.5 and 50 per cent, respectively. Under the starved lubrication condition, compared with mechanical honing, the laser texturing technique could reduce the wear scar depth of the cylinder by 34.3 per cent.

\section{References}

Kligerman, Y., Etsion, I. and Shinkarenko, A. (2005), "Improving tribological performance of piston rings by partial surface texturing", Transactions of the American Society of Mechanical Engineers, fournal of Tribology, Vol. 127 No. 3, pp. 632-638.

Kovalchenko, A., Ajayi, O., Erdemir, A., Fenske, G. and Etsio, I. (2004), "The effect of laser texturing of steel surfaces and speed-load parameters on the transition of lubrication regime from boundary to hydrodynamic", Tribologv Transactions, Vol. 47 No. 2, pp. 299-307.

Kovalchenko, A., Ajayi, O., Erdemir, A., Fenske, G. and Etsio, I. (2005), "The effect of laser surface texturing on transitions in lubrication regimes during unidirectional sliding contact", Tribologv International, Vol. 38 No. 3, pp. 219-225.

Meng, F., Zhou, R., Davis, T., Cao, J., Wang, Q.J. and Liu, J. (2010), "Study on effect of dimples on friction of parallel surfaces under different sliding conditions", Applied Surface Science, Vol. 256 No. 9, pp. 2863-2875.

Rapoport, L., Moshkovich, A., Perfilyev, V., Lapsker, I., Halperin, G., Itovich, Y. and Etsion, I. (2008), "Friction and wear of MoS2 films on laser textured steel surfaces", Surface and Coatings Technology, Vol. 202 No. 14, pp. 3332-3340.

Ronen, A., Etsion, I. and Kligerman, Y. (2001), "Friction-reducing surface-texturing in reciprocating automotive components", Tribology Transactions, Vol. 44 No. 3, pp. 359-366.

Ryk, G., Kligerman, Y. and Etsion, I. (2002), "Experimental investigation of laser surface texturing for reciprocating automotive components", Tribology Transactions, Vol. 45 No. 4, pp. 444-449.

Ryk, G., Kligerman, Y., Etsion, I. and Shinkarenko, A. (2005), "Experimental investigation of partial laser surface texturing for piston-ring friction reduction", Tribology Transactions, Vol. 48 No. 4, pp. 583-588.

Yu, X.Q., He, S. and Cai, R.L. (2002), "Frictional characteristics of mechanical seals with a laser-textured seal face", Zournal of Materials Processing Technologv, Vol. 129 Nos. 1-3, pp. 463-466.

\section{Corresponding author}

Jian Zhan can be contacted at: zhanjian@imech.ac.cn

To purchase reprints of this article please e-mail: reprints@emeraldinsight.com Or visit our web site for further details: www.emeraldinsight.com/reprints 